\title{
Métodos cuantitativos y cualitativos para el estudio de los asentamientos urbanos
}

\author{
Sergi CuAdrado CiURANETA \\ Departamento de Geografía. \\ Universidad Autónoma de Barcelona \\ sergi.cuadrado@uab.cat \\ Antoni DurÀ GUIMERÀ \\ Departamento de Geografía. \\ Universidad Autónoma de Barcelona \\ antoni.dura@uab.cat
}

Recibido: 17 de septiembre de 2013

Enviado a evaluar: 9 de enero de 2014

Aceptado: 30 de abril de 2014

\section{RESUMEN}

El articulo presenta los principales rasgos metodológicos de una investigación sobre los procesos de urbanización y la transformación de los asentamientos urbanos en la llanura del Alt Empordà (Girona). Esta metodología ha permitido identificar un nuevo modelo urbano complejo, que se despliega sobre el territorio con nuevas pautas de urbanización. Por una parte, la elaboración cartográfica y la utilización de los SIG han hecho posible el análisis de los diferentes patrones de desarrollo urbano. Por la otra, las entrevistas permitieron profundizar en aspectos más complejos, como los factores que se encuentran detrás de las transformaciones y el papel que tienen los diferentes agentes en la dinámica urbanística y territorial. Se trata de una metodología aplicable a otras zonas costeras de Cataluña, del conjunto de España y de otras zonas de la Europa mediterránea.

Palabras clave: Tipología de los asentamientos, poblamiento, hábitat, inventario de los agentes, llanura del Alt Empordà.

\section{Quantitative and qualitative methods for the study of urban settlements}

\begin{abstract}
This paper presents the main methodological features of one research about the processes of urbanization and transformation of urban centers in the plain of the Alt Empordà (Girona). Through this methodology has been identified a new and complex urban model, which is deployed on the territory with new patterns of urbanization. On the one hand cartography and GIS have made possible the analysis of different patterns of urban development. On the other hand, the interviews allowed more complex understanding of aspects such as the factors that are behind the changes and the role that different actors in urban and territorial dynamics. This methodology is applicable to other coastal areas of Catalonia, the whole of Spain and other parts of Mediterranean Europe.
\end{abstract}

Key words: Typology of urban centers, settlement, housing, inventory of agents, Alt Empordà plain. 


\section{Méthodes quantitatives et qualitatives pour l'étude des zones urbaines}

\section{RÉSUMÉ}

L'article présente les principales caractéristiques méthodologiques d'une recherche sur les processus d'urbanisation et la transformation des centres urbains dans la plaine de l'Alt Empordà (Girona). Avec cette méthodologie doit être identifié un nouveau et complexe modèle urbain, qui est déployée sur le territoire avec nouveaux modes d'urbanisation. D'une part, l'utilisation de la cartographie et des SIG ont rendu possible l'analyse des différents modèles de développement urbain. D'autre part, les entrevues ont permis une compréhension plus complexe des aspects tels que les facteurs qui sont à l'origine des changements et le rôle que les différents acteurs dans les dynamiques urbaines et territoriales. Cette méthode est applicable à d'autres zones côtières de la Catalogne, l'ensemble de l'Espagne et d'autres parties de l'Europe méditerranéenne.

Mots clés: Typologie des centres urbains, le peuplement, l'habitat, l'inventaire des agents, Alt Empordà plaine.

\section{INTRODUCCIÓN}

El objetivo de este texto es presentar las principales líneas metodológicas de una investigación ${ }^{1}$ a lo largo de la cual se han examinado los procesos de urbanización y la transformación de los asentamientos, desde mediados del siglo XX hasta la primera década del XXI, en la llanura del Alt Empordà; un ámbito situado en el noreste de Cataluña, en el extremo septentrional de la Costa Brava, que incluye veintiún municipios (Figura 1). Se trata de una zona de contrastes, donde se despliegan el turismo, la agricultura y las actividades de conservación, y entran en contacto los espacios urbanizados turísticos y no turísticos, los espacios agrícolas y los espacios protegidos de interés natural (Saurí et al., 2000; Pavón et al., 2003).

La que se presenta aquí es una metodología de carácter múltiple, que ha combinado diversos métodos: análisis bibliográfico y documental, análisis cartográfico, análisis estadístico, trabajo de campo y análisis a partir de entrevistas. Como se puede ver, la investigación ha conjugado métodos cuantitativos y cualitativos; un hecho que era necesario para abordar, con suficiente profundidad, una cuestión tan compleja y transversal como el análisis de las características del modelo territorial y urbanístico del territorio que ha servido de base para el estudio.

Así pues, a través de este artículo, se aporta una metodología que puede ser útil, como lo ha sido para el Empordà, para analizar otras zonas costeras, especialmente de la Europa mediterránea, situadas en las periferias de las principales regiones urbanas y que hayan experimentado desarrollos urbanísticos de cierta magnitud.

\footnotetext{
${ }^{1}$ Este artículo se basa en la tesis doctoral La Metropolitanització a la plana de l'Alt Empordà. Exemple d'un nou model territorial a Catalunya (Cuadrado, 2012), cuyos directores han sido los profesores Antoni Durà y Helena Estalella. Dicho trabajo se ha enmarcado en el grupo de investigación INTERFASE (SGR 2009-1027), del cual es investigadora principal la Dra. Françoise Breton.
} 
Figura 1. Municipios de la llanura del Alt Empordà

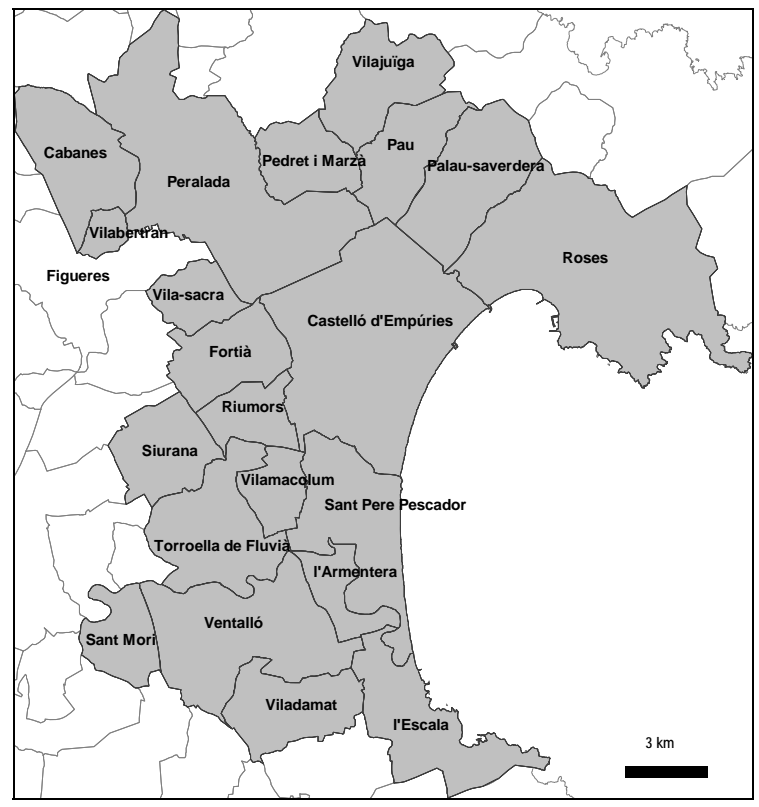

Fuente: Elaboración propia.

En las páginas que siguen se explican los principales rasgos metodológicos del trabajo en lo que se refiere a la cartografía y a las entrevistas. Estos dos métodos son aquellos a los que ha dedicado más tiempo y esfuerzo, pero también los que se han mostrado más útiles para el análisis de estas temáticas.

\section{EL ANÁLISIS CARTOGRÁFICO Y A TRAVÉS DE LOS SIG'S}

La elaboración cartográfica y la utilización de los SIG han permitido el análisis de los diferentes patrones de desarrollo urbano. La superficie urbanizada es la variable alrededor de la cual gira el estudio. Esto justifica que los datos que hacen referencia a esta variable sean nuevos, generados ex profeso, ya que el análisis del crecimiento de la superficie urbanizada se veía como un elemento crucial para el estudio de los asentamientos. Por ello el análisis cartográfico y la utilización de los SIG resultaban tan necesarios. A través de estas técnicas se ha podido medir el crecimiento de la urbanización, caracterizar los diferentes tipos de asentamientos y valorar aspectos como su localización en relación a la costa o a las vías de comunicación. Los datos de superficie urbanizada se han obtenido a partir de la fotointerpretación y la digitalización sobre ortoimágenes. El resultado ha sido la generación de unas capas georeferenciadas que posibilitan el análisis de los cambios en la superficie y la localización de los asentamientos. 


\subsection{LA DEFINICIÓN DE UNA TIPOLOGÍA DE LOS ASENTAMIENTOS}

El análisis de los usos del suelo es una de las aplicaciones más extendidas de los SIG, y existe una ingente cantidad de aportaciones que van en esta línea, hasta el punto que se pueden encontrar trabajos (Serra Ruiz, 2002; Martí, 2005; Serra Llobet, 2011) realizados con técnicas similares y para áreas cercanas, y en parte coincidentes, con el ámbito objeto de este estudio. La diferencia es que, al tratarse, en aquellos casos, de estudios del conjunto de los usos del suelo, a menudo se presta menor atención a los diferentes tipos de configuraciones urbanas.

Sin embargo, cada vez más han ido surgiendo numerosas aportaciones que, a través de los SIG, analizan los diferentes modos de urbanización, con enfoques, metodologías y niveles de detalle diversos, tanto en contextos más próximos (Nasarre y Bahía, 2006; Catalán et al., 2008; Aguilera, 2010; Valera et al., 2011; Santos y García Lázaro, 2012) como en contextos más alejados (Akbari et al., 2003; Huang et al., 2007; Chorianopoulos et al., 2010; Salvati et al., 2012).

Para realizar la caracterización de los asentamientos, se definió una tipología que posteriormente se ha aplicado al territorio. Previamente se llevó a cabo el análisis de una selección de bibliografía sobre los tejidos urbanos y el crecimiento de las ciudades. La bibliografía sobre estas cuestiones es muy amplia, ya que multitud de escuelas han trabajado estos temas, tanto en España como en el plano internacional. No obstante, la selección se limitó al ámbito catalán, para recoger experiencias realizadas sobre el mismo contexto territorial que se debía analizar.

De esta manera, los trabajos clásicos de autores como Iglésies (1958) y Llobet (1958), entre otros, fueron útiles para la comprensión de los asentamientos de origen tradicional. A su vez, las aportaciones realizadas en los años setenta desde la geografía, por Capel (1975), sirvieron para comprobar cómo la trama urbana se puede descomponer en elementos que responden a diferentes fases de su evolución. De la misma manera, los trabajos llevados a cabo desde la arquitectura, en el Laboratorio de Urbanismo de Barcelona (LUB), sirvieron para comprender como clasificar cada forma de crecimiento urbano en función de la distribución en el tiempo de los procesos de parcelación, de urbanización y de edificación (Solà Morales, 1993).

A principios de los ochenta, también desde la arquitectura, destaca la aportación de Barba Casanovas (1981), que analiza la relación de los nuevos crecimientos con el núcleo histórico, con las condiciones topográficas y con la infraestructura del territorio. En otra línea se encuentran los trabajos del geógrafo Vilagrasa $(1984,1991)$ que, centrandose en los procesos de transformación de la ciudad, de su estructura y de su paisaje, hacen énfasis en la alternancia de etapas de extensión horizontal y etapas de densificación y crecimiento vertical.

Otro tipo de aportaciones, casi siempre desde la arquitectura, pero a menudo con la participación de geógrafos, consisten en trabajos aplicados, en forma de atlas, que constituyen buenos ejemplos de la definición y la aplicación de una tipología de los diferentes tejidos urbanos. En este sentido, se pueden mencionar el trabajo del Servicio de Información y Estudios Territoriales de la MMAMB (1995), que constituye un completo balance de la región de Barcelona, desde múltiples puntos de 
vista, y con abundante material cartográfico y estadístico; los estudios dirigidos por Guàrdia, Monclús y Oyón (1995), realizados desde un punto de vista más historicista, que se centran en las principales ciudades españolas y portuguesas; y los trabajos dirigidos por Serratosa (1999), que en su momento habían de servir de base para el Plan Territorial Metropolitano de Barcelona, y que constituyen una amplia diagnosis territorial y urbanística de la región de Barcelona.

En esta misma línea cabe destacar los estudios realizados, desde la Escuela de Arquitectura del Vallès, por Font, Llop y Vilanova (1999), que definen una serie de categorías (agregados, filamentos, difusiones, etc.) para tipificar las nuevas tipologías de expansión en los territorios metropolitanos y que, en cierto modo, suponen una actualización de las definidas en los años setenta por el LUB. Otra evolución de esta línea de trabajo es la aportación de Busquets et al. (2003), donde se introduce el componente turístico en el análisis de las formas de crecimiento urbano, o el volumen publicado por Font et al. (2006), en el que la experiencia y la metodología de la Escuela de Arquitectura del Vallés se conjugan con la del Servicio de Información y Estudios Territoriales de la MMAMB. Finalmente, el libro de Barba Encarnación y Mercadé (2006) constituye un paso más en este esfuerzo, pero su estudio se centra exclusivamente en las formas urbanas de baja densidad. Así, se distingue entre los procesos de ocupación del suelo popularmente conocidos por "urbanizaciones" y los "crecimientos en baja densidad" que, a pesar de presentar una forma similar, plantean una problemática diferente. Este criterio utilizado a la hora de analizar los tejidos de baja densidad, y de discriminarlos ${ }^{2}$, supone uno de sus principales puntos fuertes.

Para acabar, de ésta etapa más reciente también hay que mencionar los trabajos, realizados desde la geografía, sobre los procesos de dispersión de las grandes ciudades. Es el caso de Muñoz (2005), y su estudio de la producción residencial de baja densidad en la provincia de Barcelona, entre los años 1985 y 2001, donde se diferencia entre las diversas tipologías de vivienda: vivienda unifamiliar (aislada o adosada) y vivienda plurifamiliar o en bloque.

Es a partir de la consulta de estas obras, que se ha complementado con el análisis del planeamiento urbanístico del área estudiada, y el trabajo de campo, imprescindible

\footnotetext{
${ }^{2}$ Al hablar de urbanizaciones se haría referencia a un elemento urbano "aislado morfológicamente y funcionalmente, donde la tipología dominante es la residencial unifamiliar aislada", que se caracterizan porqué "son diferenciables del núcleo de población, ya que están separados y no son fácilmente accesibles a pie "(Barba Encarnación y Mercadé, 2006, p. 22). Otra característica que define las urbanizaciones es que aparecen "en un momento de escaso control urbanístico y legitimadas a posteriori por el planeamiento" (Barba Encarnación y Mercadé, 2006, p. 23). En cambio, otras formas de "crecimientos en baja densidad (con casas adosadas o como expansión del núcleo)" son "resultado de un planeamiento y gestión municipales determinados", teniendo en cuenta, no obstante, que las diferencias entre éstos y las urbanizaciones "no son sólo tipológicas entre aisladas y adosadas "(Barba Encarnación y Mercadé, 2006, p. 23).
} 
para captar algunas de las características más específicas de los elementos urbanizados, que se llegó a definir una tipología de los asentamientos.

Para la construcción de la tipología se utilizaron dos conceptos de la geografía clásica, como son los de poblamiento y hábitat. Por poblamiento, se entendió el tipo de estructura interna de las áreas urbanas, tanto desde el punto de vista morfológico (en función de la disposición de las calles y demás espacios públicos y los espacios parcelados o edificados) como desde el punto de vista funcional. En cuanto al hábitat, se fijó la atención en las características de las viviendas en función de su configuración física, su disposición dentro de la parcela y su uso. En cierto modo, se recogió el reto que lanzaba a principios de los años noventa Mendizàbal (1991), cuando apuntaba que, aunque los geógrafos se habían ocupado de "las nuevas tendencias del poblamiento", no se había recuperado el propio término de "poblamiento".

\subsection{LA DESCRIPCIÓN DE LA TIPOLOGÍA}

Intentando, pues, conjugar el análisis de los tipos de poblamiento y de hábitat, se definió una tipología según la cual se puede diferenciar, en primera instancia, entre dos grandes tipos de asentamientos:

- Unos asentamientos de tipo tradicional, que se caracterizan por su carácter compacto y su relativa alta densidad, así como por su diversidad en cuanto a usos y actividades, y por el hecho de haberse configurado de una forma lenta e integrada.

- Unos nuevos tipos de as entamientos que vienen determinados por su carácter extensivo, su baja densidad, por ser altamente especializados en relación con su uso, y por haber aparecido en un período muy corto de tiempo.

Esta distinción en base al concepto de "tradicional", entre los asentamientos con un origen antiguo y unas características diferentes a las de los asentamientos aparecidos de forma más reciente, es una terminología comúnmente utilizada en un buen número de aportaciones. En este sentido, la metodología aplicada en el Programa de planificación territorial impulsado por la Generalitat de Catalunya a partir de 2003, y que se puede encontrar en el Plan Director Territorial del Empordà (DPTOP, 2006) -subsumido posteriormente en el Plan Director Territorial de las Comarques Gironines (DPTOP, 2010)-, vino a confirmar esta diferenciación, debido a que los planes distinguen entre los "núcleos históricos y sus extensiones" que son el resultado de un largo proceso de formación y las "áreas especializadas", que provienen de actuaciones concretas, y que pueden ser polígonos, urbanizaciones, equipamientos, etc. 
Entrando más en detalle, se puede hacer referencia a las categorías que se describen a continuación. En cuanto a los tipos del poblamiento, se pueden distinguir los siguientes:

- Núcleo trad icional: las partes más antiguas de los pueblos, situadas normalmente en el centro del casco urbano, que en la mayoría de casos estuvieron amuralladas, y que se caracterizan por su alto grado de compactación. En los municipios más grandes y dinámicos estas áreas aparecen hoy muy transformadas, tanto en el aspecto físico como en el funcional.

- Crecimiento del núcleo tradicional: crecimientos que en su momento se constituyeron en relación con la evolución de la actividad agrícola. Se materializaron por continuidad de la trama urbana preexistente, siguiendo los ejes de acceso a la población, y a menudo integraban las masías dispersas cercanas al casco urbano. Se caracterizan por la menor compacidad respecto al núcleo tradicional, y por su heterogeneidad tanto desde el punto de vista físico como funcional.

- Ensanche: aquellas zonas del casco urbano que, en su día, se desarrollaron a partir de la iniciativa de la Administración y de una forma unitaria, en base a unas normas de ordenación marcadas por el Ayuntamiento. Se caracterizan por disponerse a partir de una malla regular de manzanas de edificios con formas más o menos geométricas. En ellos se combinan, sobre todo, usos residenciales y comerciales.

- Urbanización de tipo tu rístico: su aparición y su localización estuvieron estrechamente ligadas al turismo y la segunda residencia. Por este hecho, se encuentran al margen de la estructura territorial y urbanística anterior. Se pueden situar sin solución de continuidad con el núcleo preexistente, o en terrenos urbanizados lejos de éste. Se caracterizan, a priori, por la combinación de usos residenciales, de alojamiento, de restauración, usos comerciales y lúdicos, etc.

- Camping: tienen su razón de ser única y exclusivamente en el turismo. A menudo son vistos como una infraestructura de alojamiento pero también se pueden considerar parte de la superficie urbanizada. Aunque se caracterizan por la ausencia de edificación, sí que presentan cierto grado de urbanización, ya que cuentan con un trazado de calles (aunque a menudo sin pavimentar) y la provisión de algunos servicios (alumbrado, abastecimiento de agua, electricidad, etc.).

- Áreas residenciales de baja densidad : áreas de nuevo trazado que se sitúan a continuación de los núcleos urbanos preexistentes, y que suponen una ruptura con las formas del poblamiento tradicional. Se caracterizan por realizarse a partir de la acción del planeamiento, por su carácter extenso y por su baja densidad. Se encuentran ocupadas básicamente por usos residenciales 
$\mathrm{y}$, en general, tienen que ver con la búsqueda de las mejores condiciones de la vivienda a un precio comparativamente más ajustado ${ }^{3}$.

- Zonas industriales, comerciales y de equipamientos: incluyen las grandes áreas correspondientes a este tipo de instalaciones, que son fácilmente identificables y que se caracterizan por localizarse en relación con las condiciones de visibilidad y accesibilidad que les confieren las vías de comunicación. Son muy características las instalaciones de tipo escaparate, situadas a lo largo de las principales carreteras.

A su vez, los diferentes tipos de hábitat se pueden clasificar de la siguiente manera:

- Edificios en tre medianeras: edificaciones que se disponen entre muros comunes a dos edificios contiguos. Generalmente ocupan toda la fachada de la parcela y se encuentran alineadas a los viales, formando hileras de edificaciones o manzanas cerradas con patio interior. Pueden ser de carácter unifamiliar, como sucede en los pueblos más pequeños, o plurifamiliar, y entonces son más habituales en los núcleos más grandes y desarrollados. En la planta baja a menudo presentan usos distintos del residencial.

- Edificación en bloque : edificación constituida por viviendas de carácter plurifamiliar pero, en este caso, con bloques aislados que presentan una forma regular y unitaria. Generalmente su uso es residencial, aunque a veces se pueden encontrar usos comerciales. En ámbitos como el que nos ocupa, los bloques se sitúan sobre todo en las urbanizaciones de tipo turístico, como sucede con los característicos edificios pantalla, situados en primera línea de mar.

- Unifamiliares adosadas: edificaciones con uso exclusivo de vivienda, y que corresponden a una única unidad familiar. La denominación de adosadas hace referencia a su disposición alineada -o en hilera- con otras viviendas de las mismas características. Se trata de promociones unitarias y su ordenación se hace en función de unos determinados parámetros de ocupación de la parcela, dejando espacios libres de uso privado delante, detrás o delante y detrás de la edificación.

- Unifamiliares aisladas: edificaciones exclusivamente residenciales, también unifamiliares, donde los parámetros de ordenación, en función de la ocupación de la parcela, definen el mantenimiento de unas distancias de separación con las parcelas vecinas, por los cuatro costados. Proliferan en las urbanizaciones de tipo turístico, y, también, en las áreas residenciales de baja densidad. Ahora bien, dentro de esta categoría se incluyen, también, las

\footnotetext{
${ }^{3}$ En su momento no se identificó, en el área de estudio, la contrapartida a las áreas residenciales de baja densidad, es decir, los crecimientos residenciales de alta densidad, conformados por bloques de vivienda plurifamiliares, que sí se podían encontrar, por ejemplo, en muchos municipios de la Región Metropolitana de Barcelona (Muñoz, 2005).
} 
tradicionales casas de campo, que en su origen combinaban usos residenciales y agrícolas, y que suelen aparecer en los crecimientos de los núcleos tradicionales.

- Tiendas, caravanas y bungalós: los tipos de hábitat propios de los campings, que se caracterizan por la ausencia de edificación. Se encuentran ocupados por instalaciones de carácter móvil, como las tiendas de campaña y las caravanas o, en el caso de que haya edificaciones, éstas son de carácter muy provisional, como es el caso de los llamados bungalós.

- Diverso: el tipo de hábitat que se ha asignado a las zonas industriales, comerciales o de equipamientos, donde las edificaciones son de tipo muy variable (naves industriales, almacenes, etc.), y que raramente cuentan con un uso residencial, ya que lo que las define es, precisamente, su uso productivo, comercial, etc.

- Zonas con un bajo grado de consoli dación: aquellas zonas ya urbanizadas (con el trazado de las calles, la provisión de los servicios, etc.) pero donde aún no se ha construido, al menos de forma mayoritaria. Casi siempre corresponden a las zonas de más reciente urbanización, aunque en algunos casos, como sucede con algunas urbanizaciones turísticas, pueden permanecer años con un elevado número de parcelas vacías.

Como se puede ver, con esta tipología se puede diferenciar entre unos tipos tradicionales del poblamiento y unos nuevos tipos de poblamiento $\mathrm{y}$, de forma paralela, entre unos tipos de hábitat de alta densidad y unos tipos de hábitat de baja densidad. Asimismo, la tipología permite una clasificación jerárquica (Tabla 1), ya que las diferentes categorías se pueden estructurar de la siguiente manera:

- Los tipos tradicionales del poblamiento comprenden los núcleos tradicionales y sus extensiones (los crecimientos del núcleo tradicional y las zonas de ensanche), mientras que los nuevos tipos de poblamiento incluyen los tipos ligados al turismo (urbanizaciones y campings), las áreas residenciales de baja densidad, y las zonas industriales, comerciales o de equipamientos.

- Los tipos de hábitat d e alta densidad comprenden los edificios entre medianeras y la edificación en bloque, mientras que los tipos de hábitat de baja densidad engloban las viviendas unifamiliares aisladas y adosadas. Al margen quedan los otros tipos de hábit at, como los que se pueden encontrar en los campings (tiendas, caravanas y bungalós), aquellos correspondientes a las zonas industriales, comerciales o de equipamientos, clasificados con un tipo de hábitat diverso, además de las zonas con un bajo grado de consolidación. 
Tabla 1. Tipología de los asentamientos, según el poblamiento y el hábitat.

\begin{tabular}{|l|l|}
\hline Poblamiento & Hábitat \\
\hline Tipos tradicionales del poblamiento & Alta densidad \\
\hline Núcleo tradicional & Edificios entre medianeras \\
\hline Crecimiento del núcleo tradicional & Edificación en bloque \\
\hline Ensanche & Baja densidad \\
\hline Tipos ligados al turismo & Unifamiliares adosadas \\
\hline Urbanización de tipo turístico & Unifamiliares aisladas \\
\hline Camping & Otros tipos \\
\hline Áreas residenciales de baja densidad & Tiendas, caravanas i bungalós \\
\hline Zonas industriales, comerciales i de equipamientos & Diverso \\
\hline
\end{tabular}

Fuente: Elaboración propia.

\subsection{LA APLICACIÓN DE LA TIPOLOGÍA AL ÁMBITO DE ESTUDIO}

Esta tipología se aplicó al territorio mediante la fotointerpretación y la digitalización sobre ortoimágenes, con el apoyo de material adicional (planeamiento urbanístico, cartografía de referencia, etc.) y la verificación mediante el trabajo de campo. Todos los trabajos se han realizado con el SIG MiraMon (Pons, 2004), que permite la generación y manipulación de cartografía diversa y de diferentes tipos de imágenes.

El análisis ha incluido tres hitos temporales (1957, 1997 y 2004), para los que se ha contado con tres series de fotografías aéreas y ortoimágenes, con diferentes características (Tabla 2). Sin embargo, todos los trabajos de digitalización se realizaron sobre las imágenes correspondientes a la última fecha: las ortoimágenes 1:5.000 del Instituto Cartográfico de Cataluña del año $2004^{4}$. En cambio, las

\footnotetext{
${ }^{4}$ Estas eran las imágenes más recientes disponibles cuando se realizó la fotointerpretación. Se obtuvieron a través de la página web del Instituto Cartográfico de Cataluña, donde desde hace unos años se pueden conseguir los diferentes productos digitales que produce el organismo, que se pueden descargar en un formato (MrSid) fácilmente convertible a MiraMon.
} 
fotografías del vuelo americano de 1957 y las ortofotografías del SIG Oleícola del Ministerio de Agricultura, Pesca y Alimentación (MAPA) del año $1997^{5}$, se usaron solo como referencia visual (Figura 2). Se procedió así para evitar la problemática de las diferencias métricas y de resolución existentes entre las tres series, evitando las variaciones en el $\mathrm{RMS}^{6}$, y que una parte de las diferencias atribuidas a la evolución de las áreas urbanizadas fueran, en realidad, causadas por las divergencias entre las imágenes de base. Este hecho, el de usar para la digitalización una única base cartográfica, fue posible gracias a las especiales características -el carácter prácticamente irreversible - de la superficie urbanizada, ya que, a diferencia de otros usos del suelo, como señala Martí (2005), una vez unos terrenos han sido urbanizados es difícil -y realmente poco frecuente- que estos se liberen y se vuelvan a renaturalizar?

Todos los trabajos de digitalización se hicieron, pues, sobre las ortoimágenes del ICC, que son en color y tienen una elevada resolución ( 0,5 metros/píxel), lo que permitió digitalizar con una escala de trabajo muy detallada (1:1.000 aproximadamente). La digitalización se inició en la fecha más reciente, para después ir cartografiando los cambios hacia atrás, mediante operaciones de sustracción. Las causas de proceder en orden inverso al cronológico fueron el mayor detalle y calidad de las imágenes de base, la mayor disponibilidad de información de referéncia y la facilidad de ir al campo a comprobar los resultados. El criterio utilizado para discriminar la superficie urbanizada fue que en los terrenos se hubiera realizado la apertura de las calles y la provisión de los servicios (pavimentación, alumbrado, etc.), independientemente del grado de consolidación. En este sentido, tal como señala Carreras (2002, p. 29), como el consumo de suelo se produce cuando se urbaniza, "para elaborar mapas de consumo de suelo es necesario delimitar los territorios que están dotados de alguna fase de urbanización (...), tanto si están edificados como si no lo están". Por lo tanto, dentro de la superficie urbanizada también se incluyen los

${ }^{5}$ Las fotografías aéreas de 1957 se escanearon y corrigieron geométricamente. En cambio, las ortofotografías del SIG Oleícola (MAPA), de las cuales se tuvo que solicitar la cesión de uso, ya se encontraban en formato digital, y corregidas geométricamente, cosa que facilitó su tratamiento y utilización.

${ }^{6}$ El RMS (Root Mean Square), o sea, el valor cuadrático medio (o media cuadrática) es el estadístico que se utiliza para conocer el error con que se ha realizado la corrección geométrica de las fotografías, es decir, la diferencia entre el valor estimado y el valor observado para cada uno de los puntos muestrales utilizados en el proceso (Chubieco, 1996).

${ }^{7}$ La desaparición de la superficie urbanizada y la consecuente renaturalización puede ser más habitual en áreas de montaña, como los Pirineos, donde los procesos de abandono por parte de la población pueden llevar, en situaciones extremas, al derrumbamiento progresivo e incluso a la desaparición del asentamiento (Guirado, 2008). En cambio, en esta área y sus zonas aledañas sólo se han dado unos pocos casos de procesos de desurbanización, por otra parte emblemáticos, como el de la urbanización La Pletera de Torroella de Montgrí (Romagosa, 2001) o el del Club Mediterranée en Cadaqués (Musquera, 2004). 
viales, los vacíos intersticiales y los espacios verdes tanto públicos como privados ${ }^{8}$. Esto es importante porque, en función del criterio empleado, a la hora de la digitalización, los resultados obtenidos pueden ser diferentes, tal como han advertido algunos autores (por ejemplo, Solans, 2002). Además, en el caso de la superficie urbanizada, esta cuestión también influye en la asignación cronológica de los crecimientos, debido a la diferenciación temporal que muchas veces existe entre las operaciones de parcelación, urbanización y edificación, y que puede conducir al error, al confundir la consolidación de la edificación con la ocupación del suelo, de adjudicar a etapas más recientes ocupaciones que ya habían sido comprometidas con anterioridad (Carreras, 2002; Solans, 2002; Ferrer, 2003).

Tabla 2. Principales características de las fotografías aéreas y ortoimágenes utilizadas en la fotointerpretación

\begin{tabular}{|c|c|c|}
\hline \multicolumn{2}{|l|}{ Bases usadas como referencia visual } & \multirow{2}{*}{$\begin{array}{l}\text { Base usada en la } \\
\text { digitalización }\end{array}$} \\
\hline Fotografías del vuelo americano & Orto fotografías del SIG oleícola & \\
\hline Fecha del vuelo: 1957 & Fecha del vuelo: 1997 & Fecha del vuelo: 2004 \\
\hline \multirow[t]{2}{*}{ Producción: Ejercito americano } & Producción: MAPA & Producción: ICC \\
\hline & Escala del vuelo: 1:40.000 & Escala del vuelo: 1:37.500 \\
\hline Escala del producto (aproximada): 1:32.000 & Escala del producto: 1:10.000 & Escala del producto: $1: 5.000$ \\
\hline $\mathrm{B} / \mathrm{N}$ & $\mathrm{B} / \mathrm{N}$ & Color natural \\
\hline Formato: Papel & Formato: Digital & Formato: Digital \\
\hline Escaneo i corrección: Grupo de investigación INTERFASE & Corrección: En origen & Corrección: En origen \\
\hline Resolución: 1 m. & Resolución: 1 m. & Resolución: 0,5 m. \\
\hline
\end{tabular}

Fuente: Elaboración propia.

${ }^{8}$ Por ello no se han contemplado, como parte de la superficie urbanizada, aquellas edificaciones que se levantan de forma aislada en el territorio, sin que se produzca la urbanización, y que se encuentran en un régimen de suelo no urbano, o en zonas de suelo urbanizable aún por desarrollar. En cambio, sí se ha incluido el terreno ocupado por los campings, ya que aunque en éstos no se produce una edificación, sí hay un cierto grado de urbanización y la provisión de algunos servicios. La decisión de incluir los campings en la superficie urbanizada se vio reafirmada por el planeamiento urbanístico de algunos de los municipios de la zona, donde el camping es considerado como una categoría más dentro de la zonificación del suelo urbano. 
El tamaño mínimo de los polígonos delimitados, así como el de los cambios entre las diferentes fechas reflejados, fue de $500 \mathrm{~m}^{2}$, siguiendo el criterio del Mapa de cubiertas del suelo de Cataluña (Ibáñez et al., 2002). Los límites de las áreas urbanas se trazaron, siempre que era posible, siguiendo las calles. Cuando no lo era, la delimitación se hizo recorriendo los límites de las edificaciones, o los límites de las parcelas ya consolidadas. En el caso de la presencia de parcelas por consolidar, no se consideraron, a efectos de cambios en los límites de la superficie urbanizada, aquellas distancias lineales inferiores a $30 \mathrm{~m}$.

Respecto a la asignación de las diferentes categorías, primero se cartografiaron las piezas urbanas según los tipos del poblamiento, y posteriormente se asignó el tipo de hábitat más representativo a cada una de ellas, aunque esto no excluye que puedan darse otros, por ejemplo, unifamiliares aisladas en una zona catalogada como de edificios entre medianeras o edificación en bloque en una zona ocupada mayoritariamente por unifamiliares aisladas. La asignación sólo del hábitat predominante en una pieza urbana con un determinado tipo del poblamiento se debe a que la variable cartografiada fue, como se ha dicho, la superficie urbanizada y no la superficie construida, y a que no se llegó a discriminar edificación por edificación.

Figura 2. Fragmento de las fotografías aéreas y ortoimágenes utilizadas en la fotointerpretación (1957-1997-2004) ${ }^{9}$

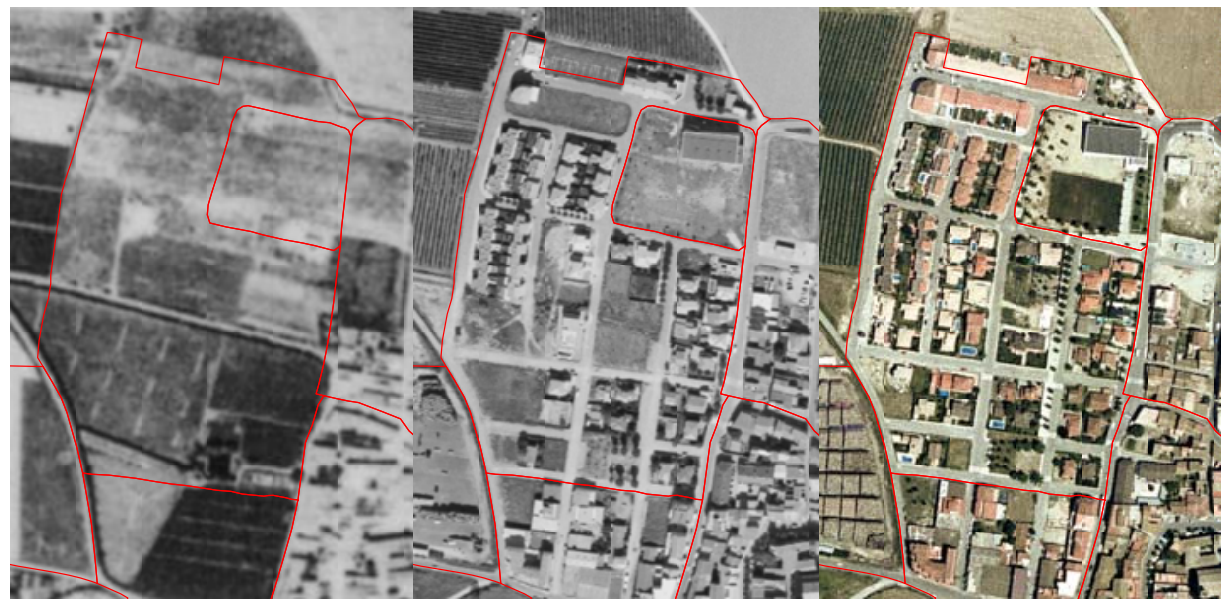

Fuente: Elaboración propia

${ }^{9}$ Por encima de las fotografías se puede ver el vector correspondiente a la digitalización de la superficie urbanizada de 1997. 
Figura 3. Superficie urbanizada (1997) y crecimientos urbanísticos 1997-2004, según los tipos del poblamiento y los tipos de hábitat
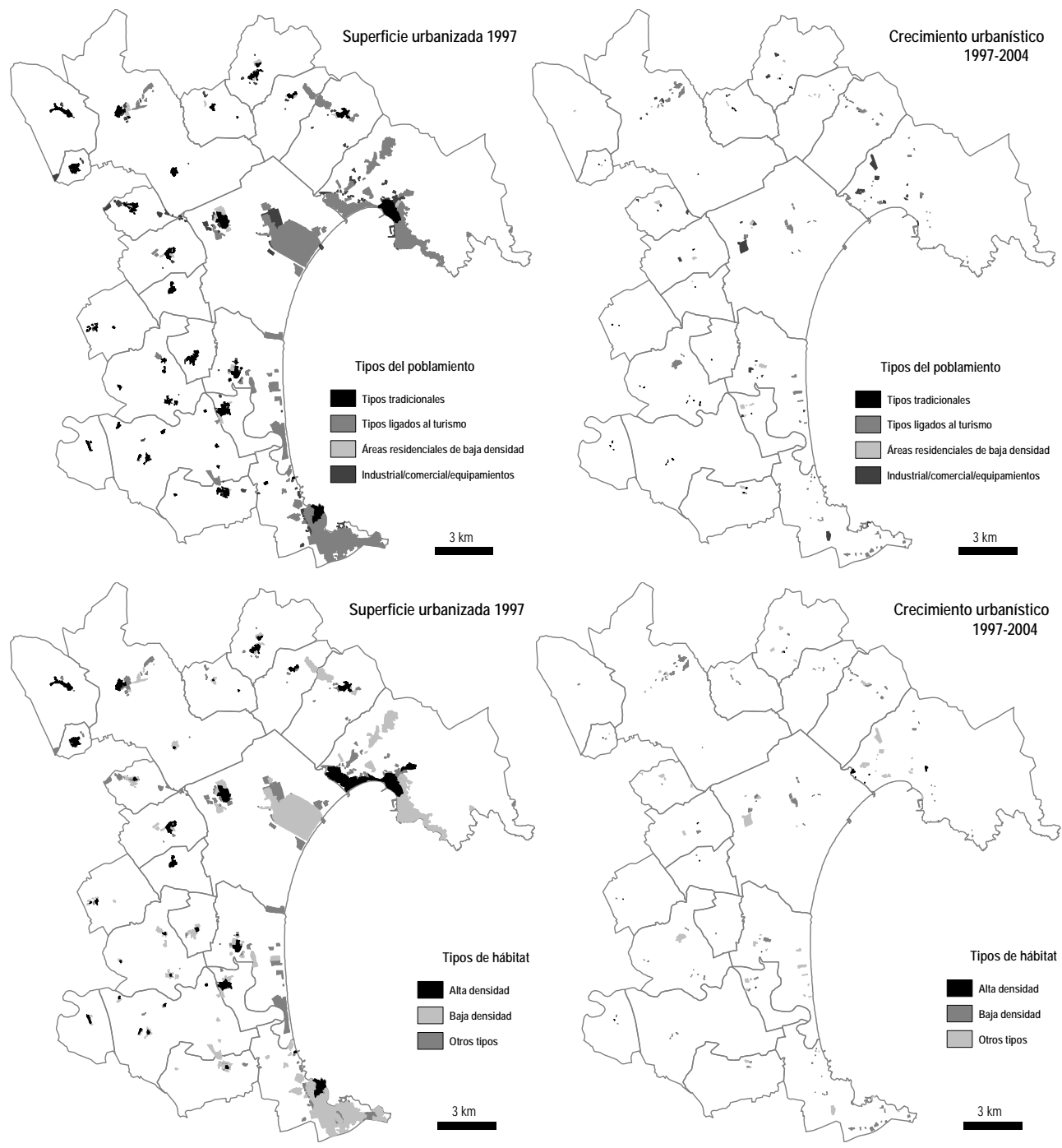

Fuente: Elaboración propia

Al trabajar con un SIG, toda esta información se fue registrando en la base de datos asociada a la capa gráfica georeferenciada que se iba generando, conforme se iba digitalizando (sirva de ejemplo la Figura 3), lo cual después permitió realizar, además del análisis de los cambios en la superficie y la localización de los diferentes tipos de asentamientos -mediante la explotación estadística de los datos de superficie, que se 
analizaron junto con los que hacían referencia a otras variables, obtenidos de otras fuentes (censos, padrón, etc.)-, una serie de ejercicios más complejos, que aportaron elementos de interpretación adicionales. Por ejemplo, se procedió al examen de la relación de la superficie urbanizada con la línea de costa, las vías de comunicación, los espacios de interés natural o las superficies con más de un $20 \%$ de pendiente.

\section{EL ANÁLISIS CUALITATIVO, MEDIANTE ENTREVISTAS}

El análisis cartográfico y mediante los SIG supuso un esfuerzo importante, pero eso no fue motivo para que los resultados obtenidos no se relacionaran con otros datos e informaciones. La decisión de utilizar otros métodos, se tomó porque no se quería llevar a cabo el análisis de las transformaciones sólo desde un punto de vista físico, haciendo referencia únicamente a aspectos como la magnitud o la localización de los asentamientos. Fue así como los resultados cartográficos se completaron, entre otros elementos, con la información cualitativa extraída a partir de una serie de entrevistas. Las entrevistas permitieron obtener una información más concreta, ayudando a aclarar incertidumbres que no se acababan de dilucidar con los datos numéricos, pero también sirvieron para profundizar en aspectos más complejos, como los factores que se encuentran detrás de las transformaciones y el papel que tienen los diferentes agentes en la dinámica urbanística y territorial.

\subsection{LA REALIZACIÓN DE LAS ENTREVISTAS}

Después de sospesar diferentes posibilidades, se optó por entrevistar a una serie de informantes considerados clave, que actuaran como portavoces acreditados de diferentes colectivos y organizaciones, descartando las entrevistas a personas individuales, que sólo pudieran hablar de su propia experiencia.

A partir de un trabajo previo (análisis de bibliografía reciente sobre el área, trabajo de campo y recopilación de artículos aparecidos en prensa) se confeccionó una selección de los colectivos a entrevistar, con la que se trató de abarcar a los diversos sectores implicados en la dinámica territorial del área, tratando de captar las diferentes ópticas posibles. Por otra parte, se trató de entrevistar a personas que pudieran hablar del conjunto del territorio, y no sólo de municipios en concreto, aunque, simultáneamente, se intentó contactar con personas de lugares donde se dieran dinámicas diferentes.

Una vez elaborado el listado, se contactó con las personas seleccionadas. En algunas ocasiones, las personas contactadas sugirieron otros nombres, algunos de los cuales finalmente también entraron a formar parte de la lista de posibles entrevistas. Por ello, aunque no se empleó la técnica de "bola de nieve", sí se puede decir que se contó con la implicación de algunos de los entrevistados y entrevistadas, y que hubo un cierto trabajo en red. Finalmente, se entrevistó a veinticinco personas vinculadas a diferentes instituciones, organizaciones y colectivos: administraciones, colegios 
profesionales, asociaciones empresariales, sindicatos, asociaciones de vecinos y otras entidades de tipo cívico (Tabla 3).

Tabla 3. Relación de las entrevistas realizadas

\section{Entidad / Organismo}

\begin{tabular}{|l|}
\hline Administraciones \\
\hline Ayuntamiento de Castelló d'Empúries \\
\hline Ayuntamiento de Sant Pere Pescador \\
\hline Ayuntamiento de Torroella de Fluvià \\
\hline Ayuntamiento de Viladamat \\
\hline Ayuntamiento de Vilajuïga \\
\hline Parque Natural de los Aiguamolls del Alt Empordà \\
\hline Patronato de Turismo Costa Brava Girona \\
\hline Servicios Territoriales de Urbanismo de Girona \\
\hline Asociaciones sectoriales i de empresarios \\
\hline Asociación de Empresarios de Actividades de Hostelería del Alt Empordà \\
\hline Asociación de Pagesos i Cortalers de Castelló d'Empúries \\
\hline Cámara de Comercio, Industria y Navegación de Girona \\
\hline Comunidad de Regantes de la Muga Dreta \\
\hline Gremio de Promotores i Constructores de Edificios de Girona \\
\hline
\end{tabular}

\section{Colegios profesionales}

Colegio de Agentes de la Propiedad Inmobiliaria de Girona i Provincia

Colegio de Aparejadores i Arquitectos Técnicos de Girona

Colegio de Arquitectos. Delegación del Alt Empordà

\section{Sindicatos}

Comisiones Obreras. Delegación del Alt Empordà

Unió de Pagesos. Delegación del Alt Empordà

Unión General de Trabajadores. Delegación del Alt Empordà

\section{Asociaciones i entidades cívicas}

Asociación de Vecinos i Usuarios de Bon Relax

Asociación Al-Jamaa (Sant Pere Pescador)

Asociación de Vecinos de Palau-saverdera

Asociación de Vecinos del Barri El Temple

Plataforma Cívica contra la Construcción Masiva de Castelló d'Empúries

Plataforma Salvem l'Empordà

Fuente: Elaboración propia. 
Las entrevistas consistieron en unos diálogos abiertos, en los cuales las personas entrevistadas aportaron su visión sobre una diversidad de aspectos como la idoneidad de los crecimientos urbanísticos, las causas de estos crecimientos, las motivaciones de los diversos flujos migratorios que se despliegan sobre el área, el papel de los diferentes agentes implicados en los crecimientos, la evolución de las dinámicas territoriales, las perspectivas de futuro, etc.

\subsection{LA CONFECCIÓN DEL INVENTARIO DE LOS AGENTES}

A la hora de abordar el papel desempeñado por los diferentes colectivos, se tuvo que hacer un paso más, a fin de estructurar el análisis, como es la realización de un inventario de los agentes, esto es, de todos aquellos actores que, de una manera $u$ otra, intervienen en los procesos de crecimiento urbanístico.

Este inventario se confeccionó a partir del bagaje previamente adquirido, mediante la lectura de bibliografía sobre el área de estudio, la realización del trabajo de campo y la recopilación de noticias de prensa, pero también a través del análisis de bibliografía específica, y del propio contenido de las entrevistas. Así, uno de los pasos más importantes fue el análisis de una selección de bibliografía sobre esta cuestión. Como en el caso de la definición de la tipología de los asentamientos, la selección bibliográfica se circunscribió al contexto catalán.

En primer lugar se consultaron obras que se caracterizan por entender la ciudad como un producto social. Se trata, por ejemplo, de los trabajos de Capel (1974), para quien la producción del espacio urbano es el resultado de las prácticas de unos agentes que actúan dentro del sistema capitalista y que, con sus intereses, modelan el crecimiento urbano. Capel identifica, como agentes, a los propietarios de los medios de producción, a los propietarios del suelo, a los promotores inmobiliarios y las empresas de construcción y, finalmente, a los organismos públicos. En la misma línea, Roca y Massana (1972) analizan el papel de las clases hegemónicas y los factores dominantes en el proceso de urbanización. Para estos autores, los agentes que, con su actuación, configuran la realidad urbana son los grandes propietarios urbanos, las grandes empresas, el Estado y los agentes públicos locales. Tatjer (1979), a su vez, analiza el papel de los propietarios de bienes inmuebles en la organización del espacio urbano, teniendo en cuenta la diversidad de formas de la propiedad urbana y sus transformaciones. Finalmente, Solà Morales (1974) se centra en los propietarios del suelo y su apropiación de las plusvalías, en el caso concreto de las áreas de urbanización marginal de la Barcelona de los años sesenta y setenta.

Dentro de esta corriente, resulta de especial interés la comunicación presentada por Teixidor (1978), en el Debate Costa Brava, donde analiza los agentes que intervinieron en el proceso de urbanización de la costa, y que quedan tipificados como los propietarios de suelo, los promotores privados, los constructores, los técnicos y gestores, los usuarios, la administración pública y la población en general. De unos años más tarde, destaca también la figura de Vilagrasa (1984), que analiza tanto a los agentes privados, que se apropian de las rentas territoriales, y que habrían 
evolucionado desde el tradicional propietario de suelo hasta el promotor inmobiliario profesional, como a las instituciones, que deben orientar el proceso de acumulación derivado de la producción del espacio urbano.

Después de un cierto paréntesis, a partir del año 2000 parece haber una reanudación del estudio de los agentes urbanos. En primer lugar, Capel (2005) analiza el juego que se establece entre las administraciones y la iniciativa privada, al tiempo que introduce la figura de los técnicos, que también desempeñan un papel relevante. Esta introducción de elementos en cierto modo alejados del análisis de la lógica del sistema capitalista parece ser una de las características de éste periodo, en el que adquiere mayor peso el examen del papel de técnicos y profesionales, de asociaciones y entidades y de los medios de comunicación. Aún con todo, no se olvida el papel de los agentes económicos, como los promotores, que en esta época experimentan cambios importantes: infiltración de capital extranjero, creciente vinculación con el sistema financiero, diversificación de las áreas de negocio y implantación en otros territorios, distintos del de origen, incluyendo el ámbito internacional (Sánchez, 2003).

Así, en estos años se pueden encontrar aportaciones donde el componente económico todavía tiene importancia, como en el caso de Boixader (2005), que identifica como los agentes que intervienen en la renovación del barrio del Poblenou de Barcelona a la Administración, las empresas industriales y de servicios, los agentes promotores e inmobiliarios, los propietarios de suelo, los propietarios de techo ${ }^{10} \mathrm{y}$ los ciudadanos en general. En la misma línea, González Reverté (2004) se fija en el sector inmobiliario, la Administración local y los grupos conservacionistas cuando analiza el proceso de urbanización del Baix Penedès. En cambio, otros estudios sitúan más el foco en otros agentes, diferentes de los económicos. Es el caso de Cruz (2006), que al analizar los conflictos urbanísticos, cuya resolución acaba incidiendo en el planeamiento y, por tanto, en la construcción de ciudad, identifica como actores a las plataformas de ciudadanos, las asociaciones de vecinos, los grupos de defensa del territorio, los expertos independientes, los medios de comunicación y las administraciones locales.

\subsection{AGENTES INCLUIDOS EN EL INVENTARIO}

A partir de estas lecturas, y con la aportación definitiva de las entrevistas, se confeccionó el inventario de los agentes que intervienen en la dinámica urbanística y territorial del área analizada. A continuación se aporta una breve descripción de cada uno de ellos:

\footnotetext{
${ }^{10}$ Que, a diferencia de los propietarios de suelo, forman parte de los consumidores del espacio urbano, por motivos residenciales, no meramente productivos. De hecho, los propietarios de techo constituirían un grupo de transición, entre propietarios y ciudadanía (Boixader, 2005).
} 
- Las administraciones públicas, la local y la autonómica, son las que ejercen las competencias urbanísticas. Los ayuntamientos son los encargados de definir los futuros crecimientos, y de velar para que las actuaciones emprendidas por propietarios y promotores se ajusten a la normativa. La Generalitat tiene competencias sobre la ordenación territorial y de carácter supramunicipal, ejerce el control de los planeamientos municipales y presta asistencia técnica y jurídica a los municipios más pequeños. Así pues, las administraciones son las que establecen la normativa que regula la actuación de los privados, corrigiendo las posibles deficiencias de ésta y salvaguardando los intereses de la ciudadanía.

- Las plataform as de defensa y los $\mathbf{m}$ ovimientos vecinales que, junto con otros colectivos, conforman la llamada sociedad civil, hacen de contrapunto a las administraciones ya que, con sus acciones y reivindicaciones, las presionan para conseguir lo que, desde su punto de vista, supone unas mejores condiciones de vida para la ciudadanía. Se trata de un conjunto compuesto por diferentes tipos de entidades (plataformas de ciudadanos, asociaciones de vecinos, grupos de defensa del territorio, etc.), que interaccionan y colaboran entre ellas -así como con otros actores, como los medios de comunicación-, compartiendo informaciones y recursos o diseñando estrategias, aunque a veces puedan mantener posiciones divergentes.

- Los agentes privados vinculados a la actividad urbanística, incluyen a una serie de colectivos que intervienen en el territorio con el objetivo de conseguir una rentabilidad económica. Se trata de los propietarios de suelo, que buscan maximizar el valor del suelo, vendiéndolo o especulando con él, y de los constructores, que son los que llevan a cabo la edificación. No obstante, cada vez ha tomado mayor peso la figura del promotor; agente que impulsa y financia las obras de edificación, generalmente para su venta. Así, los promotores serían los responsables, junto con los constructores, de la producción física del espacio urbano. Estos agentes privados proponen a la Administración local proyectos de desarrollo urbanístico, en base a las posibilidades que les ofrece la ordenación urbanística vigente.

- Los principales sector es económicos : en muchas aportaciones, entre los agentes que intervienen en la producción de la ciudad se hace referencia a los propietarios de los medios de producción, ya sean empresas industriales o de servicios, que necesitan suelo para desarrollar sus actividades, y que así entran en conflicto con otros posibles usos. Desde este punto de vista, se ha creído conveniente realizar una aproximación al papel que desempeña, respecto a los crecimientos urbanísticos, el tejido empresarial de los principales sectores económicos del área, que tradicionalmente han sido las actividades agropecuarias y el turismo. 


\section{CONSIDERACIONES FINALES}

En este artículo se han presentado los principales rasgos metodológicos de una investigación que se ha realizado sobre los procesos de urbanización y la transformación de los asentamientos en la llanura del Alt Empordà (Girona) y que ha permitido identificar un nuevo modelo urbano complejo, que se despliega sobre el territorio con nuevas pautas de urbanización.

Del uso de los diferentes métodos de diversa naturaleza, cuantitativos y cualitativos, se pueden desprender algunas reflexiones, útiles para la aplicación de esta metodología en otros estudios.

a) La cartog rafía y los S IG han sido de gran utilidad para cuantificar y caracterizar los cambios de la superficie urbanizada y los diferentes tipos de asentamientos, a través de una aportación metodológica, como es la definición de una tipología de los asentamientos, basada en los conceptos de poblamiento y hábitat. Esta tipología se ha aplicado al territorio, obteniendo como resultado una cartografía elaborada expresamente para la investigación, a través de la fotointerpretación y la digitalización sobre ortoimágenes. La utilización de la cartografía y los SIG era necesaria, ya que la superficie urbanizada es la variable entorno a la cual gira la investigación, de modo que su análisis se convierte en un elemento crucial para la compresión de los cambios en la disposición de los diferentes tipos de asentamientos. La principal virtud del uso de la cartografía y los SIG, tal y como se ha planteado, ha sido el elevado nivel de detalle con que se ha realizado la digitalización, a fin de representar con la máxima exactitud la superficie urbanizada. Es cierto que el hecho de que el área analizada sea relativamente reducida $\left(338,9 \mathrm{~km}^{2}\right)$ ha contribuido a hacerlo posible, y también que la que se presenta aquí es una investigación de largo recorrido (una tesis doctoral). En este sentido, el principal inconveniente ha sido, precisamente, la laboriosidad que implican los trabajos cartográficos, en comparación con otros métodos de análisis, debido no solo al detalle con que se han llevado a cabo, sino también a la elevada complejidad que conlleva la discriminación cartográfica de los diferentes patrones urbanísticos. Otro de los puntos fuertes del planteamiento con que se ha usado este tipo de análisis ha sido la recuperación, para el análisis territorial, de dos conceptos de la geografía clásica como los de poblamiento y hábitat, que se han aplicado al territorio mediante herramientas tecnológicas como los SIG. La doble perspectiva que ha dado la utilización de estos dos conceptos, a la hora de proceder al estudio de los asentamientos, ha dado una mayor riqueza a la investigación, permitiendo análisis cruzados entre una u otra perspectiva.

b) Las entrevistas han servido para obtener una cantidad ingente de información; una información, además, muy rica en matices. Desde este punto de vista, la realización de las entrevistas también ha demostrado ser un método útil, y necesario, a la hora de profundizar en aspectos más complejos, como son las causas de las transformaciones y el papel de los diferentes colectivos implicados en la dinámica urbanística y territorial; un aspecto, este último, abordado a partir de la confección de un inventario 
de los agentes. Además, el hecho de entrevistar a informantes cualificados ha permitido captar, con un número relativamente reducido de entrevistas, un amplio abanico de puntos de vista. Quizás uno de los puntos débiles de este tipo de análisis ha sido que la mayoría de las instituciones que se han entrevistado (sindicatos, patronales, colegios profesionales, etc.) desarrollan su actividad en contextos más bien locales y regionales, ya que estas organizaciones son las que se encuentran más al alcance, además de la Administración, que es directamente accesible, y de las entidades, que tienen mucho interés en dar a conocer su labor. En cambio, no se entrevistó a aquellos agentes de mayor magnitud y alejados del territorio, como son las grandes promotoras que operan en ámbitos internacionales, los grandes grupos de inversores o los grandes propietarios absentistas de tierras agrícolas, a los que difícilmente se puede acceder, ya sea por su carácter a veces poco definido, o incluso poco transparente, o por la lejanía de sus centros de decisión. Cabe señalar, también, que las entrevistas adolecen de un cierto sesgo, puesto que lo recogido en ellas, en realidad, es la verbalización por parte de los entrevistados y las entrevistadas de los posicionamientos de las organizaciones, instituciones o colectivos a los que representan, y que están en función de una estrategia y unos intereses determinados. Ahora bien, estas circunstancias se han tenido en cuenta en la fase de análisis de las entrevistas, de manera que se ha sido consciente que el contenido de estas, a veces, debe leerse entre líneas.

c) Una aproximación metodológica de carácter múltiple . Por lo tanto, el autentico punto fuerte de esta investigación es la aproximación metodológica, de carácter múltiple, que se ha utilizado. Este enfoque metodológico, a pesar de los costes en términos de tiempo y esfuerzo, se vislumbraba del todo necesario, para encarar el estudio de una cuestión tan amplia, tan compleja y tan transversal como es ésta. Por otro lado, ha sido precisamente esta combinación de métodos diversos, cuantitativos y cualitativos, la que ha permitido ir consolidando los resultados, entrando cada vez más en detalle: desde el estudio más general y con un alcance temporal más largo (1950-1996), hasta el estudio más detallado y realizado sobre un periodo de tiempo mucho más corto (1996-2006). En este sentido, los métodos cuantitativos permiten dimensionar muy bien la magnitud de las transformaciones territoriales, y lo que ha aportado el uso del SIG es la imagen de dichos cambios. Los métodos cualitativos, a su vez, tienen una gran capacidad explicativa, de manera que las entrevistas han aportado información sobre los factores y las causas, y han permitido hacer una aproximación a la cuestión de los agentes, además de dar algunos detalles sobre los procesos. Así pues, cada uno de los métodos utilizados -el artículo se ha centrado en la cartografía y las entrevistas, pero se podría hablar también del análisis estadístico, del bibliográfico o del trabajo de campo- ha aportado elementos y matices diferentes, a la vez que complementarios. En definitiva, el artículo se ha planteado como una propuesta metodológica para el estudio de los asentamientos urbanos, realizada a partir del estudio del caso de la llanura del Alt Empordà, con la que se pretende poner en valor esta metodología compuesta. Futuras investigaciones servirán para ver de 
que manera este enfoque metodológico puede ser extrapolable a otras áreas urbanas en crecimiento, especialmente, zonas litorales con características similares.

\section{BIBLIOGRAFÍA}

AGUILERA, F. (2010): Aplicación de métricas de ecología del paisaje para el análisis de patrones de ocupación urbana en el Área Metropolitana de Granada. Anales de Geografía de la Universidad Complutense, 30(2), 9-29.

AKBARI, H.; ROSE, L.S. Y TAHA, H. (2003): Analyzing the land cover of an urban environment using high-resolution orthophotos. Landscape and Urban Planning, 63(1), 1-14.

BARBA CASANOVAS, R. (1981): La forma de les ciutats catalanes. Quaderns d'Arquitectura i Urbanisme, Extra 1, 38-47.

BARBA ENCARNACIÓN, J. Y MERCADÉ, M. (2006): Les urbanitzacions a la província de Barcelona: localització i característiques dels sistemes de baixa densitat residencial. Barcelona, Diputació de Barcelona.

BOIXADER, J. (2005): La acción colectiva de los agentes urbanos en la transformación de Barcelona: aproximación al distrito 22@Barcelona. Scripta Nova. Revista Electrónica de Geografía y Ciencias Sociales, IX, 194(80).

BUSQUETS, J.; DOMINGO, M.; EIZAGUIRRE, X. Y MORO, A. (2003): Les formes urbanes del litoral català. Barcelona, Diputació de Barcelona.

CAPEL, H. (1974): Agentes y estrategias en la producción del espacio urbano español. Revista de Geografia, 8(1-2), 19-56.

CAPEL, H. (1975): Capitalismo y morfología urbana en España. Barcelona, Ediciones Asenet.

CAPEL, H. (2003): Redes, chabolas y rascacielos. Las transformaciones físicas y la planificación en las áreas metropolitanas. En Capel, H. (Ed.): La cosmópolis y la ciudad. Barcelona, Ediciones del Serbal, 211-248.

CAPEL, H. (2005): El Modelo Barcelona: un examen crítico. Barcelona, Ediciones del Serbal.

CARRERAS, J. M. (2002): La redistribució de la ciutat al territori de la Regió Metropolitana de Barcelona. Papers. Regió Metropolitana de Barcelona, 36, 25-48.

CATALÁN, B.; SAURÍ, D. Y SERRA, P. (2008): Urban sprawl in the Mediterranean? Patterns of growth and change in the Barcelona Metropolitan Region 1993-2000. Landscape and Urban Planning, 85(3-4), 174-184.

CHORIANOPOULOS, I.; PAGONIS, T.; KOUKOULAS, S. Y DRYMONITI, S. (2010): Planning, competitiveness and sprawl in the Mediterranean city: The case of Athens. Cities, 27(4), 249-259.

CHUBIECO, E. (1996): Fundamentos de teledetección espacial. Madrid, Ediciones Rialp.

CRUZ, H. (2006): Los conflictos urbanísticos: sus causas y sus protagonistas. Una reflexión a partir de la experiencia de Cataluña. Cuadernos de Geografía, 80, 183194. 
CUADRADO, S. (2012): La metropolitanització a la plana de l'Alt Empordà. Exemple d'un nou model territorial a Catalunya. Bellaterra, Universitat Autònoma de Barcelona.

DEPARTAMENT DE POLÍTICA TERRITORIAL I OBRES PÚBLIQUES (DPTOP) (2006): Pla Director Territorial de l'Empordà. Barcelona, Generalitat de Catalunya.

DEPARTAMENT DE POLÍTICA TERRITORIAL I OBRES PÚBLIQUES (DPTOP) (2010): Pla Director Territorial de les comarques gironines. Barcelona, Generalitat de Catalunya.

DONAIRE, J.A. (2005): La lògica espacial del turisme a la Costa Brava. En COAC: Debat Costa Brava. Congrés: Un futur sostenible. Girona, COAC, 218-225.

FERRER, A. (2003): Del crecimiento disperso a la ciudad razonablemente compacta. En Font, A. (Ed.): Planeamiento urbanístico. De la controversia a la renovación. Barcelona, Diputació de Barcelona, 135-150.

FONT, A.; LLOP, C. Y VILANOVA, J. M. (1999): La construcció del territori metropolità. Morfogènesi de la regió urbana de Barcelona. Barcelona, Àrea metropolitana de Barcelona. Mancomunitat de municipis.

FONT, A.; MAS, S.; MARISTANY, L.; CARRERAS, J. M. Y VALLS, J. (2006): Transformacions urbanitzadores 1977-2000. Àrea metropolitana i regió urbana de Barcelona. Barcelona, Mancomunitat de Municipis de l'Àrea Metropolitana de Barcelona.

GUÀRDIA, M.; MONCLÚS, F. J. Y OYÓN, J. L. (1995): Atlas histórico de ciudades europeas. Península Ibérica. Barcelona, Centre de Cultura Contemporània de Barcelona. Salvat Editores.

GUIRADO, C. (2008): El paisatge de l'Alt Pirineu català: entre l'abandonament del territori i la naturbanització. En IV Simposio Internacional Territorios y Sociedades en un mundo en cambio. Miradas contrastadas desde Iberoamérica. Barcelona, Universidad de Barcelona.

GONZÁlEZ REVERTÉ, F. (2004): Procés d'urbanització i desenvolupament residencial a Catalunya. Lectures territorials sobre el cas del Baix Penedès. Revista de Geografia, 3, 35-62.

HUANG, J.; LU, X.X.; SELLERS, J.M. (2007): A global comparative analysis of urban form: Applying spatial metrics and remote sensing. Landscape and Urban Planning, 82(4), 184-197.

IBÀÑEZ, J. J.; BURRIEL, J. A. Y PONS, X. (2002): El mapa de cobertes del sòl de Catalunya: una eina per al coneixement, la planificació i la gestió del territori. Perspectives Territorials, 3, 11-25.

IGLÉSIES, J. (1958): Geografia urbana. En Solé, L. (Ed.): Geografia de Catalunya. Barcelona, Editorial Aedos, Vol. I, 599-626.

LLOBET, S. (1958): La casa rural. En Solé, L. (Ed.): Geografia de Catalunya. Barcelona, Editorial Aedos, Vol. I, 481-498.

MANCOMUNITAT DE MUNICIPIS DE L'ÀREA METROPOLITANA DE BARCELONA (MMAMB) (1995): Dinàmiques metropolitanes a l'Àrea i la Regió 
de Barcelona. Barcelona, Mancomunitat de Municipis de l'Àrea Metropolitana de Barcelona.

MARTÍ, C. (2005): La transformació del paisatge litoral de la Costa Brava: Anàlisi de l'evolució (1956-2003), diagnosi de l'estat actual i prognosi de futur. Girona, Universitat de Girona.

MENDIZÀBAL, E. (1991): Les noves tendències del poblament. En Societat Catalana de Geografia: Primer Congrés de Geografia. Barcelona, Societat Catalana de Geografia, 159-178.

MUÑOZ, F. (2005): La producció residencial de baixa densitat. Barcelona, Diputació de Barcelona.

MUSQUERA, S. (2004): Club Mediterranée. Intervenció en el paisatge del Cap de Creus als anys 60. Annals de l'Institut d'Estudis Empordanesos, 37, 311-342.

NASARRE, E. Y BADIA, A. (2006): Una aproximación al crecimiento de áreas urbanas a través de fotografia aérea y de sistemas de información geográfica. La ciudad de Tarrassa como caso de estudio. Cuadernos Geográficos, 39, 185-201.

PAVÓN, D.; VENTURA, M.; RIBAS, A.; SERRA, P.; SAURÍ, D. Y BRETON, F. (2003): Land use change and socio-environmental conflict in the Alt Emporda county (Catalonia, Spain). Journal of Arid Environments, 54(3), 543-552.

PONS, X. (2004): MiraMon. Sistema d'Informació Geogràfica i software de Teledetecció. Bellaterra. Centre de Recerca Ecològica i Aplicacions Forestals.

ROCA, F. Y MASSANA, C. (1972): Estratègies urbanes i realitat urbana a la regió de Barcelona. En Artal, F. (Ed.): Economia crítica: una perspectiva catalana. Barcelona, Edicions 62, 202-233.

ROMAGOSA, F. (2001): Els Aiguamolls de l'Empordà: de la destrucció a la protecció i l'ús turístic. Estudis de Turisme de Catalunya, 9, 11-15.

SALVATI, L.; MUNAFO, M.; GARGIULO, V. Y SABBI, A. (2012): Low-density settlements and land use changes in a Mediterranean urban region. Landscape and Urban Planning, 105(1-2), 43-52.

SANTOS, J. M. Y GARCÍA LÁZARO, F. J. (2012): La vivienda unifamiliar, fenómeno característico de la ciudad dispersa. Contrastes sectoriales en la aglomeración urbana de Madrid. Anales de Geografía de la Universidad Complutense, 32(1), 153-179.

SÁNCHEZ, J. E. (2003): El mercado inmobiliario y los promotores: cambios en la gran empresa inmobiliaria. Scripta Nova. Revista Electrónica de Geografía y Ciencias Sociales, VII, 146(091).

SAURÍ, D.; BRETON, F.; RIBAS, A.; LLURDÉS, J.C. Y ROMAGOSA, F. (2000): The ecological values of traditional land use in low-lying coastal environments: the example of the Aiguamolls de l'Empordà, Costa Brava. Journal of Environmental Planning and Management, 43(3), 277-290.

SERRA RUIZ, P. (2002): Dinàmiques del paisatge agrari a 1'Alt Empordà (19771997). Una anàlisi a partir de la teledetecció i dels Sistemes d'Informació Geogràfica. Bellaterra, Universitat Autònoma de Barcelona. 
SERRA LLOBET, A. (2011): Turning hazards into resources? Floods, wetlands and climate change in the Mediterranean coast of Spain. Bellaterra, Universitat Autònoma de Barcelona.

SERRATOSA, A. (1999): Factors clau de la planificació territorial a l'Àrea Metropolitana de Barcelona. Barcelona, Institut d'Estudis Territorials.

SOLÀ MORALES, M. de (1974): La urbanización marginal y la formación de plusvalía del suelo. Papers. Revista de Sociologia, 3, 365-380.

SOLÀ MORALES, M. de (1993): Les formes de creixement urbà. Barcelona, Edicions UPC.

SOLANS, J. A. (2002): L'ocupació de sòl en el sistema metropolità central durant el període 1980-1998. Papers. Regió Metropolitana de Barcelona, 36, 49-72.

TATJER, M. (1979): Propiedad immobiliaria y espacio urbano. Aproximación a su estudio. Revista de la Universidad Complutense, 115, 49-82.

TEIXIDOR, C. (1978): Els agents de l'urbanisme. En VVAA: Debat Costa Brava. Girona, Cambra Oficial de Comerç i Indústria, 31-34.

VALERA, A.; AÑÓ, C. Y SÁNCHEZ DÍAZ, J. (2011): Cincuenta años (1956-2006) de crecimiento urbano y degradación de suelos por sellado antropogénico en el término municipal de Valencia. Anales de Geografía de la Universidad Complutense, 31(2), 177-191.

VILAGRASA, J. (1984): Creixement urbà i producció de l'espai a Lleida (19401980). Documents d'Anàlisi Geogràfica, 5, 97-138.

VILAGRASA, J. (1991): El estudio de la morfología urbana. Geo-crítica. Cuadernos Críticos de Geografía Humana, 92, 7-45. 